\title{
DINÂMICA GEOGRÁFICA DA MOBILIDADE DO CAPITAL NA PRODUÇÃO DE CELULOSE E PAPEL EM TRÊS LAGOAS (MS)
}

\author{
geographic dynamics of capital mobility in the production \\ of pulp and paper in Três Lagoas (MS)
}

\author{
Guilherme Marini Perpetua \\ Antonio Thomaz Junior ${ }^{2}$
}

$a_{a} \boldsymbol{a}_{a a}$

\begin{abstract}
Resumo
O objetivo do presente artigo é apresentar e discutir os principais aspectos da dinâmica geográfica da mobilidade espacial do capital, envolvidos no processo recente de territorialização do monocultivo de eucalipto e da produção de celulose e papel no Município de Três Lagoas (MS) e em seu entorno regional, tendo como fundamento um aporte teórico que permite compreendê-lo como parte da processualidade contraditória do sistema de metabolismo social do capital. Neste intento, foram analisados os processos mais abrangentes que se desdobram no plano internacional e nacional envolvendo este setor produtivo, e os condicionantes internos que justificam a escolha deste subespaço para a recepção das megainversões. Conclui-se que este fenômeno é uma expressão concreta do ímpeto incontrolável da acumulação do capital, dentro da qual a mobilidade espacial funcional como um mecanismo elementar.
\end{abstract}

Palavras-chave: Mobilidade espacial do capital; Territorialização do eucalipto; Produção de celulose e papel.

\begin{abstract}
The aim of this article is to present and discuss the main aspects of the geographical dynamics of spatial mobility of capital involved in the recent process of territorialization of monoculture of eucalyptus and pulp and paper in the city of Tres Lagoas (MS) and its regional surroundings, taking as a basis a theoretical framework that allows to understand it as part of the contradictory processuality of the system of social metabolism of the capital. In this attempt, we have analyzed the broader processes that unfold at international and national levels involving this productive sector, and the internal constraints that justify the choice of this subspace for receiving the megainversions. We conclude that this phenomenon is a concrete expression of the uncontrollable momentum of capital accumulation, within which the spatial mobility works as an elementary mechanism.
\end{abstract}

Key words: Spatial mobility of the capital; Territorialization of eucalyptus; Pulp and paper production.

\begin{abstract}
Resumen
El objetivo de este artículo es presentar y discutir los principales aspectos de la dinámica geográfica de la movilidad espacial del capital involucrado en el reciente proceso de territorialización del monocultivo de eucalipto y de la producción de pulpa y papel en la ciudad de Tres Lagoas (MS) y su entorno regional, tomando como base un marco teórico que permite entenderla como parte de la procesualidad contradictoria del sistema de metabolismo social del capital. En este intento, se analizaron los procesos más amplios que se desarrollan en los ámbitos internacional y nacional relacionados con este sector productivo y las restricciones internas que justifican la elección de este subespacio para la recepción de megainversiones. Llegamos a la conclusión de que este fenómeno es una expresión concreta del impulso incontrolable de la acumulación de capital, en el que la movilidad espacial funciona como un mecanismo elemental.
\end{abstract}

Palabras claves: Movilidad espacial del capital; Territorialización de eucalipto, Pulpa y papel.

(1) Doutorando em Geografia da Universidade Estadual Paulista Júlio de Mesquita Filho, Presidente Prudente - Rua Roberto Simonsen, 305, CEP: 19060900, Presidente Prudente (SP), Brasil. Tel: (+55 1832295375 - geomarini@yahoo.com.br

(2) Bolsista Produtividade do CNPq e Prof. Dr. da Universidade Estadual Paulista Júlio de Mesquita Filho, Presidente Prudente - Rua Roberto Simonsen, 305, CEP: 19060900, Presidente Prudente (SP), Brasil. Tel: (+55 1832295375 - thomazjr@gmail.com

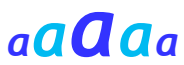

Revista da ANPEGE, v. 9, n. 12, p. 55-69, jul./dez. 2013.

ISSN 1679-768 X @ C 2003, Associação Nacional de Pesquisa e Pós-Graduação em Geografia. Todos os direitos reservados. 


\section{INTRODUÇÃO}

O momento atual inaugura um período no qual o movimento cada vez mais acelerado (de pessoas, informações, capitais) passa a ser uma característica intrínseca da dinâmica habitual da sociedade, que nele se (re)define e (re)territorializa constantemente (HAESBAERT, 2010), conferindo à esfera da circulação uma centralidade inédita na história da acumulação e da produção do espaço capitalista (SANTOS, 1994; MOREIRA, 2000).

A mobilidade espacial do capital, conquanto intensificada na atualidade, não é um fenômeno restrito a ela. Ao lado da produção de uma espacialidade cada vez mais abrangente e instrumental (SOJA, 1993), essa forma de mobilidade tem sido, desde os albores do capitalismo, um mecanismo imprescindível de postergação (temporária) dos antagonismos e contradições potencialmente mais destrutivos e inexpugnáveis do sistema de metabolismo social hegemônico (HARVEY, 2005; MÉSZÁROS, 2011).

No entanto, as transformações oriundas da crise do sistema em âmbito mundial, iniciada na década de 1970, trazem à tona um novo panorama para se pensar sobre este tipo específico de mobilidade espacial. Novas condições técnicas e políticas, embutidas no processo de reestruturação sistêmica do capitalismo, imprimem uma nova (re)divisão internacional do trabalho na era da produção flexível, com a decomposição técnica de processos produtivos e, consequentemente, o deslocamento de unidades industriais dos países centrais para os periféricos e semiperiféricos (BENKO, 1996; CHESNAIS, 1996). O mesmo movimento pode ser observado em relação ao território nacional, marcado pela reorganização produtiva e pela desconcentração industrial que conduz à crescente especialização do trabalho nos lugares (SANTOS; SILVEIRA, 2006).

Neste contexto, o fenômeno da mobilidade espacial exige novas leituras que transcendam a noção de mera descrição e mensuração de fluxos ou deslocamentos físicos, tão propalada nas ciências sociais e na história do pensamento geográfico (MARANDOLA JÚNIOR, 2008; ROCHA, 1998). Uma análise das contradições sociais reveladas pela mobilidade espacial é o que se propõe por meio desta temática.

Partindo desses apontamentos, o objetivo do presente artigo é apresentar e discutir os principais aspectos das dinâmicas da mobilidade espacial do capital, no bojo do processo recente de territorialização do monocultivo de eucalipto e da produção de celulose e papel no Município de Três Lagoas (MS) e em seu entorno regional, tendo como fundamento um aporte teórico que permite compreendê-los como parte da processualidade contraditória do sistema de metabolismo social do capital. Seu conteúdo está disposto em três seções, além desta introdução e das considerações finais. A primeira apresenta os fatos e processos que constituem os pressupostos empíricos da pesquisa. A segunda procura delinear os principais traços do constructo teórico sobre o qual se fundamentou a análise. A terceira dedica-se a apresentação e a discussão dos resultados obtidos.

\section{A NOVA CAPITAL DO CAPITAL DA CELULOSE}

A partir da segunda metade da década de 1990, o município de Três Lagoas, localizado na porção nordeste do estado de Mato Grosso do Sul e à margem direita do Rio Paraná, passou a esboçar os primeiros traços do que tem sido, desde então, um frenético e diversificado processo de industrialização. Embora diversificado, o carro-chefe do processo são as indústrias de celulose e, em menor grau, também de papel, quer pela vultosidade dos investimentos, quer por sua expressiva participação no crescimento da economia e das exportações municipais.

O início da instalação deste tipo específico de indústria em Três Lagoas ocorreu com a chegada da Votorantim Celulose Papel (VCP) e da International Paper, que deram início a um projeto conjunto para a instalação de fábrica integrada (de celulose e papel), a partir de uma troca de ativos entre as duas empresas no ano de 2006, momento em que se deu o lançamento da pedra fundamental do então chamado complexo VCP-IP. O projeto recebeu o nome de "horizonte 1" (Figura 1) e sua 
construção levou em torno de três anos, custando cerca de R \$ 3,1 bilhões (fora base de monocultivo), parte dos quais financiados pelo Banco Nacional de Desenvolvimento Econômico e Social (BNDES) (KUDLAVICZ, 2011).

Em 2009, ano de sua entrada em operação, a unidade já possuía capacidade produtiva de 1,3 milhão de toneladas/ano de celulose de mercado de fibra curta branqueada, valor equivalente a $1 / 4$ da produção total da empresa (ALMEIDA, 2010) que, fundida à Aracruz Celulose no mesmo ano, recebeu o nome de Fibria e ascendeu ao posto de maior produtora mundial desta commodity.

Em 2010, a empresa Eldorado Brasil, controlada atualmente pela holding J\&F (do grupo JBS), também lançou a pedra fundamental de sua fábrica de celulose no município, um empreendimento ainda mais faraônico orçado em cerca de R $\$ 5,1$ bilhões e também financiado em grande parte (53\% do total) com aportes públicos via BNDES (BNDES, 06/06/2011). A fábrica, inaugurada no mês de dezembro de 2012, visa suplantar a capacidade produtiva da Fibria no município e foi projetada para ser a maior planta fabril deste segmento do mundo, com capacidade de 1,5 milhão de toneladas/ano.

Com isso, Três Lagoas passou a ostentar a maior produção mundial individual de celulose da atualidade, e ipso facto - somado aos anúncios de ampliação da capacidade produtiva por parte das duas empresas, cujas projeções mais otimistas calculam que atingirá 10 milhões de toneladas/ ano até 2020 - tem sido chamada pelos maiores entusiastas do modelo dentro do qual se insere de “capital mundial da celulose" (ÉPOCA NEGÓCIOS, 04/10/2010).

$\mathrm{Na}$ esteira das novas fábricas territorializa-se também o monocultivo do eucalipto em escala realmente avassaladora em Mato Grosso do Sul (Figura 2), concentrando-se, sobretudo, no território da Microrregião de Três Lagoas, constituída pelos municípios de Três Lagoas, Água Clara, Selvíria, Brasilândia e Santa Rita do Pardo (segundo a regionalização oficial do IBGE).

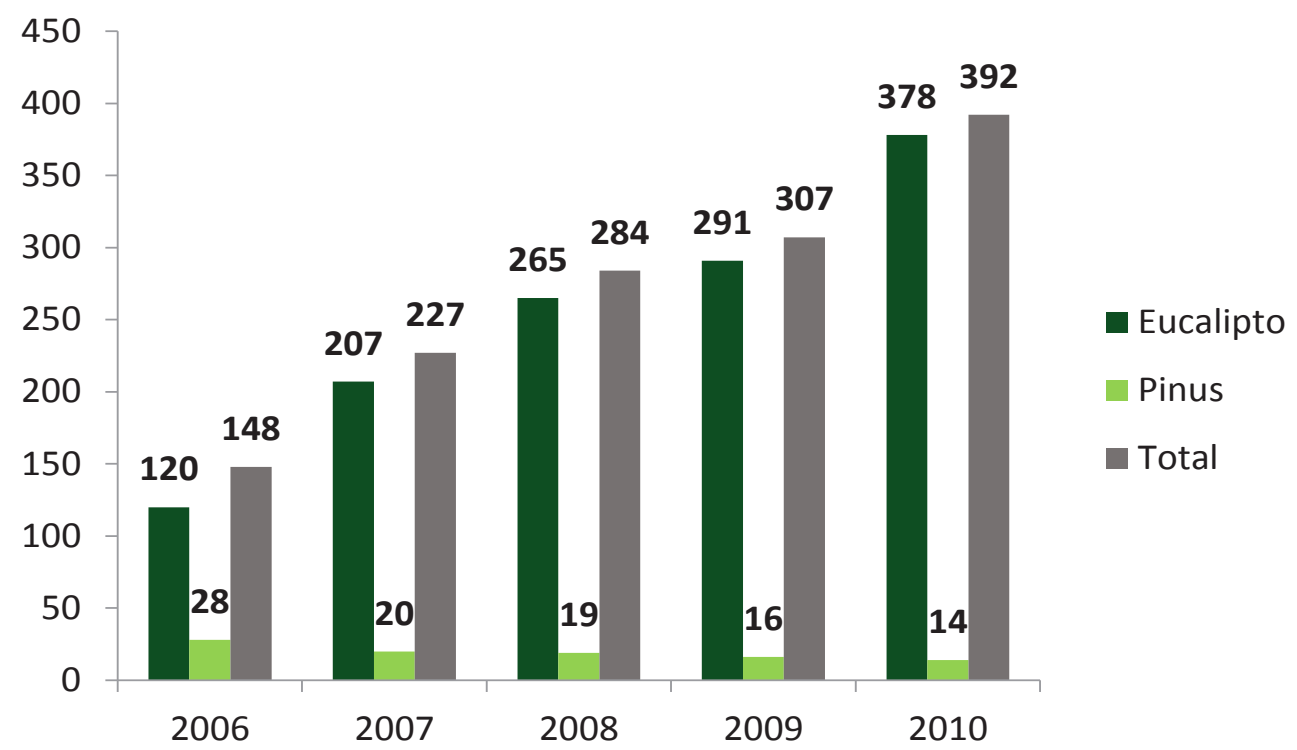

Figura 1 - Evolução da Área (ha) Plantada com Eucalipto e Pinus entre 2006 e 2010 em Mato Grosso do Sul (em mil/ha).

Fonte: REFLORE-MS. Disponível em: $<$ http://www.reflore.com.br/dados/florestas-plantadas-ms $>$ (Acesso em 05/2012). Org. pelo autor.

Em função desse crescimento repentino, segundo dados da ABRAF (2011), em 2011, mesmo diante do arrefecimento dos índices de crescimento dos estados tradicionalmente produtores, o estado de Mato Grosso do Sul atingiu a marca dos 475,5 mil/ha plantados com árvores do gênero Eucalyptus, apresentando o segundo maior crescimento de área cultivada com este gênero no País (24,3\% a mais em comparação com o ano anterior) e passando ao posto de quarto estado em área plantada no Brasil, atrás apenas de Minas Gerais (1.4 milhão/ha), São Paulo (1,03 milhão/ha) e Bahia (607,4 mil/ha). 
Contudo, para além dos recordes econômicos, o processo de mudança do uso predominantemente agropastoril do território da região, iniciado com a execução dos megaempreendimentos em questão, desencadeou uma série de transformações territoriais significativas ainda em curso e pouco (ou nada) mensuradas. A continuidade e a estagnação, que compunham e definiam a paisagem e o espaço regional, têm dado lugar à descontinuidade e ao dinamismo, com seus impactos para os homens e seu(s) território(s). Dentre eles, ganha relevo um grande aumento da população residente de Três Lagoas, que cresceu 20,2\% no curto intervalo entre 2004 e 2010 (IBGE, 2010), ao lado do qual se faz notar o aumento intermitente de uma população flutuante, composta pelos milhares de trabalhadores temporários que atuam na construção e montagem dos complexos fabris e nas áreas de plantio. Tal aumento tem resultado na saturação da infraestrutura e dos serviços básicos e na elevação dos preços dos produtos e serviços, efeitos que somados, levam à elevação do custo e a degradação da qualidade de vida dos moradores. Paralelamente, intensificaram-se o êxodo rural e a criminalidade urbana (KUDLAVICZ, 2011) e o número de veículos mais do que dobrou, segundo dados do IBGE (2010), caotizando o trânsito nas ruas e avenidas da cidade. Devido aos baixos salários e ao frequente desrespeito à legislação trabalhista nos canteiros de obras das novas fábricas de celulose e papel, uma série de greves e outras formas de manifestação, como incêndios a alojamentos, por exemplo, tornaram-se parte do cotidiano três-lagoense.

Portanto, por trás da luminosa fachada do desenvolvimento sustentável e de uma economia verde, insistentemente apregoada pelos agentes do capital e do Estado, as mazelas socioterritoriais acenam para processos mais abrangentes, os quais, neste texto, se procura compreender com o amparo da interpretação marxista sobre a mobilidade espacial do capital.

\section{A QUESTÃO DA MOBILIDADE DO CAPITAL EM SEU SISTEMA DE METABOLISMO SOCIAL}

Com a emergência histórica do sistema de metabolismo social do capital, não somente os seres humanos, mas tudo o que participa direta ou indiretamente de sua reprodução ampliada passou a movimentar-se de modo cada vez mais intenso, numa reciprocidade dialética na e da produção/ reprodução de um espaço geográfico crescentemente mais fragmentado, integrado, polarizado e desigual (SMITH, 1988; BRANDÃO, 2007).

Como explica Mészáros (2011), o sociometabolismo do capital é uma forma histórica absolutamente singular de relação dos homens entre si e com a natureza em seu intercâmbio reprodutivo, dentro da qual as mediações primárias (ou de primeira ordem), voltadas para a produção de valores de uso, são suplantadas por mediações secundárias (ou de segunda ordem), voltadas para o objetivo externo e reificado da acumulação. Esse sistema específico de mediações de segunda ordem do capital, por sua vez, conforma "[...] um todo social antagonicamente estruturado [...] por meio do sistema estabelecido de produção e troca", regido pelo imperativo do valor de troca em permanente e incontrolável expansão (Ibid., p. 67. Grifos do autor). Nele, comenta o autor, o capital não é simplesmente uma entidade material ou um mecanismo racionalmente controlável, mas é,

[...] em última análise, uma forma incontrolável de controle sociometabólico [...] uma poderosa - na verdade, até o presente, de longe a mais poderosa - 'estrutura totalizadora' de controle à qual tudo o mais, inclusive os seres humanos, deve se ajustar, e assim provar sua 'viabilidade produtiva', ou perecer, caso não consiga se adaptar (Ibid. p. 96, Grifos no original).

Neste quadro referencial, uma explicação sumária para a mobilidade do capital poderia ser encontrada na tendência inerente do próprio sistema de especialização e fragmentação da produção e, por conseguinte, do próprio trabalho no processo multifacetado, contínuo e sempre crescente de divisão social, técnica e territorial (HARNECKER, 1973). Contudo, a mobilidade do capital não é apenas um efeito ou consequência; ela possui aspectos mais profundos e estruturais em seu sistema 
sociometabólico, na medida em que evidencia sua lógica irrefreavelmente expansionista, funcionando como um mecanismo absolutamente imprescindível de postergação das suas contradições e antagonismos potencialmente mais explosivos. (THOMAZ JUNIOR, 2011).

$\mathrm{Na}$ contramão das leituras fundamentadas nas vertentes da economia política clássica ou neoclássica, bem como daquela de cariz keynesiano, com base nas quais a mobilidade é interpretada como fenômeno que deriva da liberdade e racionalidade absolutas do homem e que, em última instância, tende a levar os sistemas econômicos ao equilíbrio (GAUDEMAR, 1977; GOMES, 2009), a leitura marxiana e marxista o enxerga como processo forçado e estranhado, em última análise, alheio às aspirações individuais.

Capital e força de trabalho são os polos antagônicos, mas mutuamente implicados e imprescindíveis do sociometabolismo do capital e de seu sistema de mediações - segundo Ranieri (2001), o próprio capital é trabalho transmutado. Como tais, manifestam a mobilidade espacial no sentido indicado. O uso do conceito de mobilidade do capital, entretanto, revela-se relativamente polissêmico, na medida em que, em sentido amplo, não se restringe apenas ao fenômeno do deslocamento do capital pelo espaço geográfico, podendo designar igualmente processos de transferência do capital entre setores econômicos ou ramos diferentes da produção, ou ainda, aplicar-se às três formas assumidas por ele: o capital mercantil, o capital produtivo e o capital financeiro.

Contudo, como explica Chesnais,

o capital é [...] um valor [...] cujo objetivo é a autovalorização, a obtenção de lucro, em condições nas quais o ramo industrial, bem como a localização geográfica do comprometimento do capital têm, em última análise, caráter contingente (1996, p. 81. Grifos nossos).

Complementarmente e ainda no mesmo trecho, o autor afirma que:

[...] um dos atributos ideais do capital, que é também, mais do que nunca, um dos adjetivos concretos colocados pelos grupos, é a mobilidade, a recusa a se prender a determinadas modalidades de comprometimento setorial ou geográfico [...] bem como a capacidade de se soltar, de desinvestir tanto quanto de investir (Ibid.; Ibidem. Grifos nossos).

Assim, o expediente da mobilidade, qualquer que seja sua acepção ou forma, tem a mesma finalidade de valorizá-lo ou reproduzi-lo de modo ampliado, assumindo importância cada vez mais estratégica entre os grandes grupos empresariais na contemporaneidade.

Pode-se pensar acerca da mobilidade espacial do capital, especificamente, partindo-se de duas perspectivas escalares que, embora contidas uma na outra, revelam faces diferentes do mesmo fenômeno. Por um lado, é possível considerá-la sob o ângulo da microescala, desde o ponto de vista das decisões locacionais das empresas e/ou de seus gestores ad hoc, para os quais a seletividade espacial constitui estratégia de aumento da rentabilidade do negócio (CORRÊA, 1995), e logo, de aumento da competitividade na eterna disputa do mercado concorrencial capitalista (SINGER, 1975). Por outro lado, na perspectiva macroescalar, ou seja, do sistema como um todo, devido ao caráter inevitavelmente cíclico e desigual da acumulação capitalista, o somatório dos movimentos dos capitais fragmentários torna-se expressão do antagonismo fundante entre o capital e o trabalho. Segundo esta abordagem, e tomando por base autores como Harvey (2005) e Mészáros (2011), a mobilidade espacial seria uma forma de prorrogação da vigência do sistema do capital - ou um "ajuste", nas palavras de Harvey - através do deslocamento das suas contradições pelo espaço geográfico, o que, em contrapartida, engendra a sua tendência universalizante.

Importa salientar que, com as modificações dos mecanismos do padrão de acumulação e de geração de valor do sistema capitalista que caracterizam a emergência do chamado regime flexível, a partir da década de 1970 (ANTUNES, 1999; 2011), decorrentes das "respostas" do capital à crise experimentada naquele contexto (revolução tecnológica, novas formas de organização da produção 
e do trabalhado, introdução da política econômica neoliberal e degradação do welfare state, dentre outras) (MATTOSO, 1995; ARAÚJO, 1999), também o expediente da mobilidade fora resignificado.

Nesse sentido, retomando Chesnais (1996), destaca-se a potencialização sem precedentes da seletividade espacial que preside a mobilidade do capital, em função das novas condições técnicas e políticas do período atual, atingindo, desse modo, os cantos mais recônditos do globo e permitindo a sustentação de sua acumulação necessariamente ampliada.

\section{A INSERÇÃO DE TRÊS LAGOAS NA CADEIA PRODUTIVA MUNDIALIZADA DO PAPEL}

O período atual marca o fortalecimento e a expansão do assim chamado "complexo florestal" no Brasil, setor que em 2010 apresentou um valor bruto de produção da ordem de R $\$ 51,8$ bilhões (REPORTER BRASIL, 2011), com grande participação da indústria de celulose e papel, a qual, sozinha, faturou R\$27,5 bilhões em 2009 e estima-se que crescerá 57\% até 2020 (ÉPOCA NEGÓCIOS, 04/10/2010). Sua pujança e dinamismo econômico tem se destacado no conjunto da produção industrial nacional nas últimas décadas (Tabela 1).

Tabela 1 - Brasil: Evolução da Produção de Celulose e Papel - 1970-2010

(em milhões de toneladas)

\begin{tabular}{|lccccccc|}
\hline & & & & & & & \\
\hline Produto\Ano & $\mathbf{1 9 7 0}$ & $\mathbf{1 9 8 0}$ & $\mathbf{1 9 9 0}$ & $\mathbf{2 0 0 7}$ & $\mathbf{2 0 0 8}$ & $\mathbf{2 0 0 9}$ & $\mathbf{2 0 1 0}$ \\
\hline Celulose & 0,8 & 3,1 & 4,4 & 12 & 12,7 & 13,3 & 14,1 \\
Papel & 1,1 & 3,4 & 4,7 & 9,0 & 9,4 & 9,4 & 9,8 \\
\hline \multicolumn{1}{l}{} & & & & & &
\end{tabular}

Fonte: BRACELPA, 2011.

Nota-se uma expressiva evolução do setor destacadamente na produção de celulose, sobretudo a partir da década de 1990, período em que mais que triplicou, colocando o Brasil entre os maiores produtores mundiais. Além do volume, há outra importante distinção entre os dois segmentos em destaque. Enquanto o papel produzido no País volta-se, predominantemente, para o atendimento do mercado interno (78,9\%, em 2010), sendo a maior parte das exportações destinadas à América Latina, a produção de celulose de mercado de fibra curta branqueada é voltada majoritariamente para o mercado externo (59,1\%, no mesmo ano), marcadamente para o mercado europeu e com cada vez mais intensidade para a China, que em 2010 foi o destino de $26 \%$ das exportações brasileiras desse produto (BRACELPA, 2011), o que explicita um processo de especialização produtiva do Brasil neste segmento.

Os números também em outros aspectos contribuem para reforçar o ufanismo dos entusiastas do modelo de desenvolvimento centrado no agronegócio, fundamentado na tese da "vocação natural" do Brasil para o (mono)cultivo de árvores (o qual gostam de chamar de "florestas plantadas") e a produção de celulose. Nesse sentido, convém notar que o País apresenta produtividade e competitividade ímpares comparativamente a qualquer outro país do mundo, devido a fatores como as condições edafoclimáticas de seu território, a enorme produtividade da madeira de eucalipto $\left(44 \mathrm{~m}^{3} /\right.$ ha/ano) e seu baixo tempo de rotação (cerca de 7 anos), a disponibilidade e o baixo preço das terras e, consequentemente, o baixo custo da produção da matéria-prima (BIAZUS; HORA; LEITE, 2010).

As afirmações do presidente em exercício da Associação Brasileira de Produtores de Floresta Plantada (ABRAF), Antonio Sérgio Alípio, feitas em apresentação por ele proferida na abertura da "I Feira da Indústria de Base Florestal Sustentável de Três Lagoas", evidenciam esta autoimagem. Naquela ocasião, referindo-se aos resultados do ano de 2011, afirmou o porta-voz dos empresários do setor: 
o Brasil foi líder absoluto de competitividade no setor florestal [...] temos clima, temos capacidade de gestão, temos tecnologia, portanto, temos todas as condições de manter essa competitividade que ainda temos - e não 'tínhamos' -, mas temos o desafio de ampliá-las se quisermos efetivamente transformar o Brasil numa potência florestal, [o] que é a sua vocação (ANTONIO SÉRGIO ALÍPIO, 10/04/2012. Informação verbal. Transcrição literal).

Todavia, ampliando-se a escala de análise da produção de celulose e papel no mundo nas últimas décadas, torna-se nítido que o mesmo processo de fortalecimento de parques industriais de processamento de celulose e, atrelado a eles, de expansão do monocultivo de árvores que se verifica no Brasil, também vem ocorrendo em diversos países periféricos ou semiperiféricos do Hemisfério Sul, como o Uruguai e o Chile na América do Sul; a África do Sul, o Quênia e a Nigéria no continente africano, e a Indonésia, a Índia, a Tailândia e o Vietnã na Ásia (WRM, 2004; MORELLI, 2011). Pari passu, como comenta Pakkasvirta (2010), na mesma frequência fábricas exitosas e lucrativas têm sido fechadas nos tradicionais países produtores, como é o caso da Finlândia.

Portanto, o caso brasileiro, e dentro dele, o de Três Lagoas, deve ser entendido dentro do contexto da transformação estrutural da indústria de papel, impulsionado pela busca de um método produtivo que seja economicamente mais eficiente por parte das grandes corporações papeleiras na atualidade (PAKKASVIRTA, 2010), o que implica a transferência espacial das etapas iniciais da cadeia produtiva, constituídas pela exploração florestal e pela produção de celulose (SANTOS, 2009; MORELLI, 2011). Isso explica porque entre 1994 e 2004, por exemplo, a produção de celulose apresentou crescimento relativo de $64,4 \%$ no Brasil, $112,5 \%$ no Chile e de $150 \%$ na Indonésia, ao mesmo tempo em que decresceu 10,2\% nos EUA, 3,6\% no Japão e apresentou crescimento pífio de 3,9\% no Canadá, 18,6\% na Suécia e 24,8\% na Finlândia (BRACELPA, 2006).

A gama de fatores envolvidos direta ou indiretamente nesse processo é extensa. De modo sintético, pode-se citar a escassez de matéria-prima (florestas nativas), os altos custos de produção, as pressões ambientalistas por parte da sociedade civil organizada, e o consequente recrudescimento da legislação ambiental como principais fatores da redução da produção de celulose nos países tradicionalmente produtores do Hemisfério Norte. No Hemisfério Sul, o outro extremo do processo, apresentam-se como condicionantes as condições edafoclimáticas extremamente favoráveis e os altos índices de produtividade obtidos com as novas fontes de matéria-prima para o papel (eucalipto, pinus, acácia, principalmente), a flexibilidade da legislação ambiental, a disponibilidade e o baixo valor da terra, o baixo valor de troca da força de trabalho, e por fim, mas não menos importante, os irrecusáveis benefícios, incentivos e subsídios oferecidos pelos governos nacionais da região aos investidores interessados (DAURA, 2004; SANTOS, 2009; PAKKASVIRTA, 2010; MORELLI, 2011).

Deve-se salientar que na composição média de custos de produção da celulose, a matéria-prima (madeira) representa 41\% do custo final (BIAZUS; HORA; LEITE, 2010). Isso justifica as palavras de Robert A. Wilson, alto executivo de uma grande corporação do setor, ao afirmar que a redução dos custos com matéria-prima é "a estratégia que norteia a indústria [de celulose e papel] [...] a chave de uma competitividade diferenciadora" (apud WRM, 2004, p. 8).

A alavanca subjacente dessa transformação estrutural e da transferência espacial é o crescimento a um ritmo impressionante do consumo do papel no mundo em décadas recentes - 123,1\% nos últimos 30 anos e mais de $400 \%$ nos últimos 50 anos, segundo dados do PPI/RISI e do WRM (2004) -, cuja distribuição pelos países do globo apresenta discrepância abissal. Neste trabalho sustenta-se a hipótese de que tal aumento seja uma das expressões da intensificação contemporânea do que Mészáros (2011) chamou de taxa de utilização decrescente do valor de uso, uma das leis tendenciais que regem o funcionamento do sistema do capital e que hoje assume a forma de extrema perdularidade, desperdício e destruição. Sua essência, segundo o autor, está na "completa subordinação das necessidades humanas à reprodução do valor de troca" (MÉSZÁROS, 2011, p. 606), que se tornou possível com a "homogeneização, historicamente única, de todas as relações 
produtivas e distributivas" (Ibid., p. 624. Grifo no original), operada por intermédio de uma dupla e subsequente ruptura entre os produtores reais da riqueza (trabalhadores) e os seus materiais e instrumentos de produção (meios de produção), e entre o produto e o seu valor de uso, fazendo com que quanto menor for a taxa de utilização de uma mercadoria - ou seja, sua vida útil -, melhor será para o capital, na medida em que isso conduzirá a necessidade de sua reposição, possibilitando igualmente a aceleração do movimento de reprodução ampliada.

Por intermédio destes excertos do filosofo húngaro pode-se compreender o crescimento da produção de papel, fortemente impulsionado pelos papéis para embalagens e para a indústria da publicidade, na esteira do aumento da produção de mercadorias em geral.

Outro fato importante com relação ao aumento da produção do papel no mundo, diz respeito a sua distribuição geográfica. Quanto a isso, faz-se mister considerar a descomunal participação da China, país que ingressou de maneira voraz também neste setor, despontando como o maior produtor e um dos maiores exportadores de papel do mundo, sobretudo a partir dos anos 2000 (MONTEBELO; BACHA, 2007; BIAZUS; HORA; LEITE, 2010). Definem-se, dessa forma, as linhas de uma (re)divisão internacional do trabalho na produção de papel na qual os países periféricos ocupam o lugar de produtores da matéria-prima (madeira/celulose) com baixo valor agregado; a China se estabelece paulatinamente como o principal mercado consumidor de celulose e principal país produtor e exportador de papel; e os países centrais, destacadamente os da Europa e da América do Norte, atuam como os grandes consumidores finais do papel produzido nesta cadeia global.

À escala nacional, as ações do Estado brasileiro têm sido de fundamental importância para a inserção do Brasil nesta (re)divisão internacional do trabalho, bem como para a formatação deste setor no âmbito interno de suas fronteiras. Destacam-se, nesse sentido, a criação de medidas legais para o crescimento e o fortalecimento do setor, como o II Código Florestal Brasileiro, promulgado em 1965 (Lei No 4.771/65), a Lei No 5.106/66, que estabelecia o abatimento de imposto de renda por meio de reflorestamento; a promulgação do I Plano Nacional de Papel e Celulose (I PNPC), vinculado ao II PND (1974); a Lei No 1376/74, que estipulava incentivos ao reflorestamento via Fundo de Investimento Setorial (FISET) (SANTOS, 2009; MORELLI, 2011); e o abundante financiamento público via BNDES, instituição que, entre 1955 e 2002, aprovou ao todo a quantia de R \$ 30,9 bilhões em financiamentos para o setor (em Reais de 2001), perfazendo uma média de R\$ 1,2 bilhão por ano, sem contar as participações acionárias em diversos investimentos que também tiveram importante papel (JUVENAL; MATTOS, 2002).

Outro fato de vital importância para o estudo do caso em questão é que do ponto de vista geográfico, a indústria de celulose, que esteve fortemente concentrada nas regiões Sudeste e Sul, responsáveis por $87 \%$ de toda a produção até o final de década de 1990 (DAURA, 2004), experimenta atualmente um significativo movimento de interiorização, com a instalação de novas plantas fabris, sobretudo nas regiões Centro-Oeste, Nordeste e Norte do País. Figuram entre os fatores de atração desse movimento, além é claro, dos atributos naturais (insolação, solo, relevo, abundância hídrica), o acesso à infraestrutura de transportes multimodal e fontes de energia, os benefícios e incentivos oferecidos pelos estados e municípios, mas especialmente, o baixo preço da terra em comparação com as áreas já consolidadas (FOLHA DE SÃO PAULO, 20/10/2011).

No tocante à inserção específica de Três Lagoas nesta cadeia produtiva da celulose tornada mundial, ou seja, aos motivos que levaram a sua escolha como sítio dos megainvestimentos pelas empresas do setor, alguns condicionantes principais devem ser arrolados:

(a) Os Aspectos naturais presentes na microrregião, como o clima predominantemente tropical, caracterizado pela alta insolação e pelos índices pluviométricos suficientes para o cultivo do eucalipto; o relevo plano esculpido nas rochas sedimentares da Bacia do Rio Paraná, que favorece o corte mecanizado; os tipos de solos predominantes (Latossolo Vermelho Distrófico, 
Argissolo Vermelho Amarelo, Neossolo Quartzarênico), considerados adequados para o cultivo do eucalipto; e a abundância de água superficial e subterrânea, sobretudo pela presença do Rio Paraná e do Aquífero Guarani que permitem tanto o consumo necessário para o crescimento do eucalipto, quanto o abastecimento do caudaloso volume de água demandado pelo processo produtivo da celulose;

(b) A existência prévia de ampla base florestal de eucalipto nos municípios da microrregião, constituída desde os anos de 1980 como resultado do planejamento do Estado no período militar (1964-1985), de forma mais incisiva com o II PND e as ações via Superintendência de Desenvolvimento do Centro-Oeste (SUDECO), responsável pela formulação do Plano de Desenvolvimento Econômico-Social do Centro-Oeste (PLADESCO), que elegeu a região como área prioritária para a formação de maciços florestais através da concessão de incentivos ao reflorestamento (KUDLAVICZ, 2011);

(c) O baixo preço e a disponibilidade de terras para o cultivo do eucalipto, assim como a estrutura fundiária altamente concentrada da microrregião. Estes fatores estão ligados ao fato de que a silvicultura do eucalipto para fins de processamento industrial requer extensas áreas de terra para a constituição de bases florestais contíguas, o que facilita o gerenciamento e o corte e permite a redução dos custos com o transporte da madeira até a fábrica. Note-se, quanto a isso, que as terras da microrregião de Três Lagoas foram em sua maior parte ocupadas pela pecuária extensiva desde o início do século XX (JURADO, 2008), o que provocou forte desmatamento e degradação dos solos, reduzindo o seu valor comercial.

(d) A infraestrutura de transporte multimodal que atende a microrregião e que é polarizada por Três Lagoas, município que se localiza num verdadeiro entroncamento ferroviário (Eixo da Novoeste), rodoviário (BR 262, BR 158 e BR 395) e hidroviário (Hidrovia Tietê-Paraná, com eclusa em Três Lagoas) (Figura 3), facilitando e reduzindo os custos do escoamento da celulose até o Porto de Santos (SP), de onde segue para os mercados da América do Norte, Europa e Ásia; 


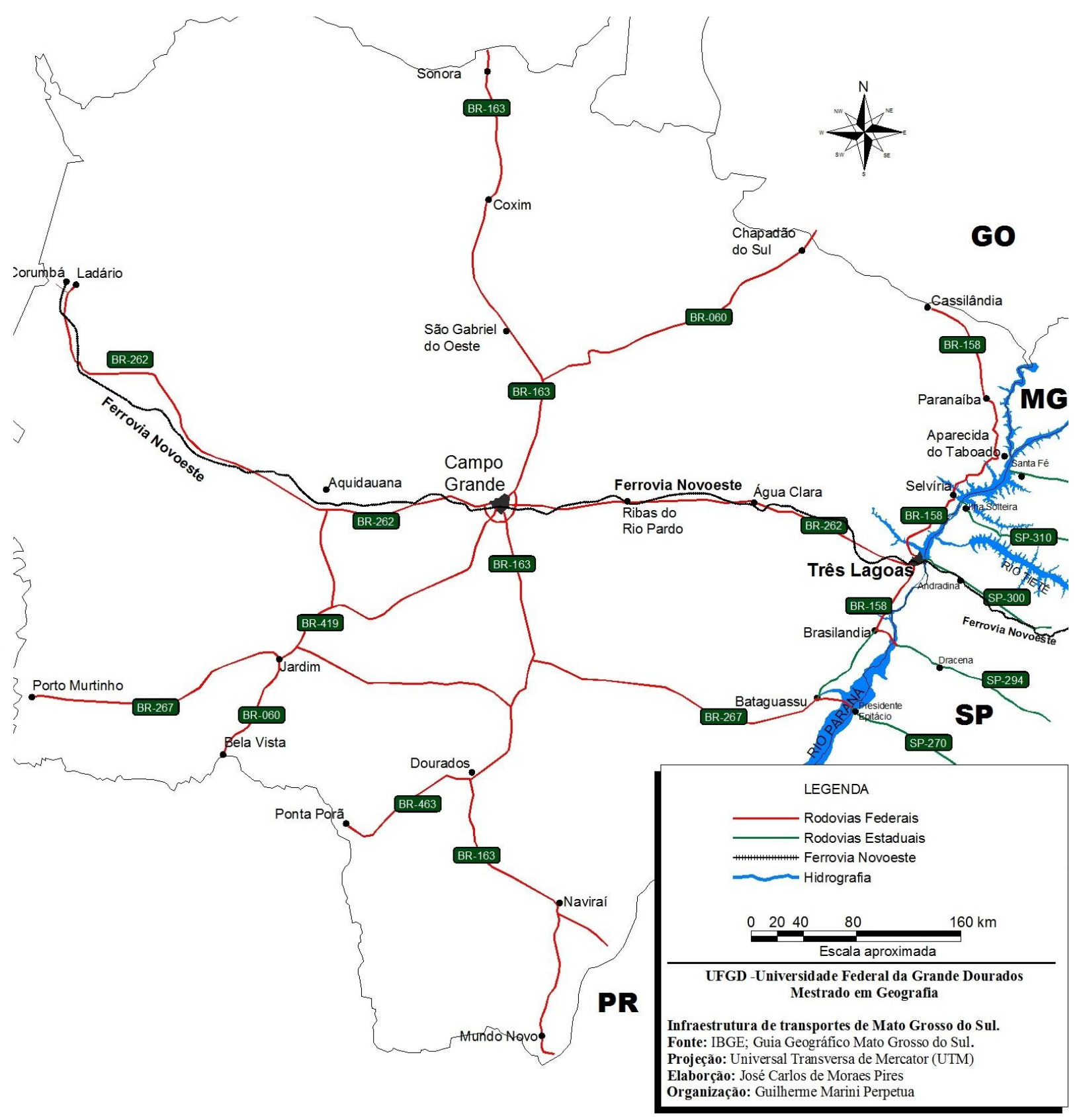

Figura 2 - Três Lagoas: situação em relação aos principais eixos de transporte de Mato Grosso do Sul. 
(e) O baixo valor de troca da força de trabalho, sua precária organização e a fraca atuação dos movimentos sociais. Quanto ao primeiro ponto, conforme Jurado (2008), pode-se mesmo afirmar que constitui forte fator de atração não só para a indústria de celulose e papel, mas para todos os ramos industriais que recentemente se instalaram no município. Veja-se a título de exemplo que em 2010, segundo dados do MTE/CAGED, enquanto a remuneração média de empregos formais na indústria de transformação em Três Lagoas era de R \$ 1.749,00 (masculino) e R \$ 873,60 (feminino), ela atingia $\mathrm{R} \$ 2.920,83$ (masculino) e $\mathrm{R} \$ 1.879,33$ (feminino) em Jacareí (SP), onde a Fibria também tem unidade de produção. No que toca ao último ponto, destaca-se que a simples "presença do MST" é apontada como fator negativo para a consolidação de um cluster madeireiro na região no Plano Estadual Para o Desenvolvimento Sustentável de Florestas Plantadas - PEF-MS, o qual será abordado a seguir.

(f) Por fim, e com maior peso, as ações do Estado nos níveis estadual e municipal em benefício do grande capital, no sentido de atrair e manter as inversões do setor em Mato Grosso do Sul e especificamente em Três Lagoas. Destacam-se, no tocante a isso, a inclusão da chamada "cadeia florestal" ou "da madeira" como área prioritária de fomento na agenda do planejamento estratégico do Governo Estadual (MATO GROSSO DO SUL/SEPLANCT, 1999; 2004); a criação de leis e decretos que estabelecem incentivos tributários às empresas no âmbito estadual, como a Lei no 093/2001 (denominada "MS-EMPREENDEDOR"), que prevê isenção de até $67 \%$ do ICMS devido por um prazo de até cinco anos para indústrias; a legislação municipal (Lei no 1955/2005) que concede isenção de impostos (IPTU, ISS) por um período de quinze anos para investimentos acima de $\mathrm{R} \$ 100$ milhões, além de outros benefícios como a doação, terraplanagem e infraestrutura básica dos terrenos para instalação industrial; e, como não bastasse, a criação pelo Governo Estadual de um conjunto de medidas que flexibilizaram a legislação ambiental e institucionalizam a volúpia territorial das empresas. São exemplos disso a Resolução SEMAC/MS nº 17/2007, que dispensa o licenciamento ambiental obrigatório para as atividades de plantio e condução das espécies florestais nativas ou exóticas para produção e corte; a elaboração do Plano Estadual Para o Desenvolvimento Sustentável de Florestas Plantadas - PEF-MS (MATO GROSSO DO SUL/SEPROTUR/ SEBRAE, 2009), que estabelece como metas estratégicas atingir 1 milhão/ha plantados com eucalipto e pinus e formar um cluster da indústria de base florestal na região (Figura 4); e a aprovação do Zoneamento Ecológico-Econômico do Estado - ZEE-MS (Lei nº 3.839/2009), que legitima e institucionaliza as metas do PEF-MS, na medida em que delimita uma extensa área a Centro-Leste do território estadual (Zona das Monções), praticamente coincidente com aquela delimitada pelo PEF-MS, na qual assegura e inclusive recomenda a expansão prioritária da "agropecuária consorciada com a silvicultura, agroindústria e indústria em geral", bem como das "[...] culturas de alta capacidade de rendimento", recomendando "[...] a utilização da agricultura mecanizada com alta tecnologia, especialmente a silvicultura produtora de madeira para móveis, celulose e energia" (MATO GROSSO DO SUL/DIÁRIO OFICIAL, 29/12/2009, p. 45 , Grifos nossos). 


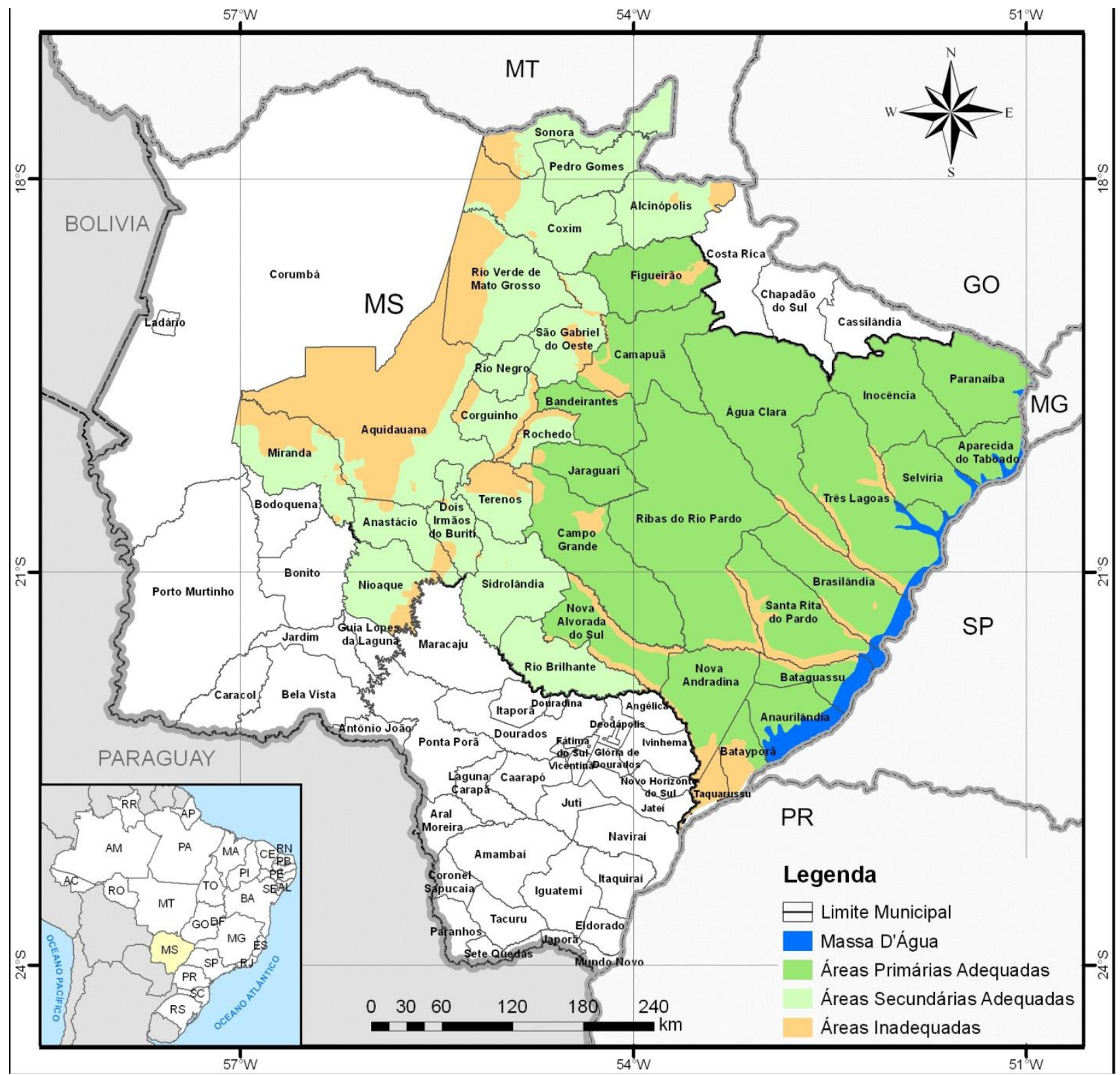

Figura 3 - Região Prioritária Para a Implantação do PEF/MS.

Fonte: PEF/MS (MATO GROSSO DO SUL/SEPROTUR, 2009).

\section{CONSIDERAÇÕES FINAIS}

Os resultados obtidos com a pesquisa permitem tecer algumas considerações. Em primeiro lugar, deve-se salientar que a territorialização do monocultivo de eucalipto e da produção de celulose - e, em menor medida, também de papel - em Três Lagoas é uma expressão concreta do ímpeto expansionista incontrolável da acumulação capitalista, personificado pelas grandes corporações do setor na atualidade. $\mathrm{O}$ expediente da mobilidade espacial do capital, ou seja, do deslocamento das inversões produtivas de um hemisfério para outro, de um país para outro ou de uma região para outra, atende não apenas à "ganância” dos grupos empresariais, mas à necessidade real de elevação da competitividade (leia-se redução de custos) no jogo encarniçado de uma concorrência elevada ao plano mundial nas últimas décadas, com o processo de mundialização da economia. É neste marco que devem ser pensadas a transformação estrutural da indústria papeleira mundial, a transferência espacial dela decorrente e o processo de interiorização da produção em solo brasileiro neste início do século XXI. 
O repertório de "vantagens locacionais" oferecido por Três Lagoas tem atuado no sentido de assegurar que o objetivo das corporações seja atingido, e neste ponto, o papel do Governo, em seus níveis estadual e municipal, mostra-se preponderante sobre os demais condicionantes, pois este se alia às empresas, colocando seus interesses acima de quaisquer outros em nome de um pretenso desenvolvimento sustentável, cujo caminho é a economia verde por elas representada. No entanto, o que se vê nem sempre é o que parece. O verde das paisagens homogêneas formadas pelos eucaliptais contíguos e a perder de vista, a grandiosidade das fábricas e da intensa expansão da maquinaria no campo, ícones do "progresso capitalista" que são per si eloquentes, funcionam tal como uma miragem, imagem irreal que se almeja alcançar e que ilude e bloqueia a percepção das inúmeras perdas para a grande maioria da população, e dos desdobramentos nefastos cujas dimensões potenciais são ainda ignoradas, enquanto o grande capital usufrui de volumosos recursos públicos, vastíssimas áreas de terras com baixo valor, caudalosos mananciais e braços humanos baratos.

Para não concluir, parafraseando o subtítulo da obra de Jussi Pakkasvirta (2011), pesquisador finlandês que se dedicou ao estudo de caso da instalação de uma fábrica de celulose em Fray Bentos (Uruguai), pode-se afirmar que a história desse processo em Três Lagoas é também uma história dada numa geografia própria da globalização; história sobre a forma como se produz um artigo indispensável (o papel) por meio da combinação hierárquica e contraditória de territórios desiguais no espaço mundial, com todas as suas consequências socioambientais. Portanto, deve ser tomada não como um objeto de crítica em si, mas como porta de entrada para a discussão de um modelo de sociedade cronicamente inviável e, no dizer de Mészáros (2007), irreformável, bem como de sua superação.

\section{REFERÊNCIA BIBLIOGRÁFICA}

ALMEIDA, R. A. de. A territorialização do agronegócio do eucalipto na região leste de Mato Grosso do Sul e o cerco à reforma agrária. In: XVI Encontro Nacional de Geógrafos (ENG), 2010. Anais... Porto Alegre: 2010. ANTUNES, R. L. C. Os sentidos do trabalho: ensaios sobre a afirmação e a negação do trabalho. São Paulo: Boitempo, 1999.

ANTUNES, R. L. C. O sistema de metabolismo social do capital e seu corolário, a alienação, na obra de István Mészáros. In. JINKINGS, I.; NOBILE, R. (Org.). István Mészáros e os desafios do tempo histórico. São Paulo: Boitempo, 2011.

ARAÚJO, T. B. de. Brasil anos 90: opções estratégicas e dinâmica regional. Revista Brasileira de Estudos Urbanos e Regionais - ANPUR. Recife, nº 2, p. 9-24. mai/Nov. 1999.

ASSOCIAÇAO BRASILEIRA DE CELULOSE E PAPEL (BRACELPA). Globalização e o futuro da indústria brasileira de celulose e papel. in: Painel madeira 2006. Brasília: BRACELPA, 2006.

ASSOCIAÇAO BRASILEIRA DE CELULOSE E PAPEL (BRACELPA). Dados do setor - Junho - 2011. Disponível em: <http://www.bracelpa.org.br/bra2/?q=node/29> (Acesso em 03/05/2011).

BENKO, G. Economia, espaço e globalização na aurora do século XXI. São Paulo: Hucitec, 1996.

BIAZUS, A.; HORA, A. B. da; LEITE, B. G. P. Panorama de mercado: celulose. In: BNDES setorial. no 32. p. 311-370. Disponível em: < http://www.bndes.gov.br/SiteBNDES/export/sites/default/bndes_pt/Galerias/ Arquivos/conhecimento/bnset/set32109.pdf> (Acesso em 06/07/2011).

BNDES. BNDES aprova financiamento de R\$ 2,7 bilhões para a Eldorado. Rio de Janeiro, 06/06/2011. Disponível em: $<$ http://www.bndes.gov.br/SiteBNDES/bndes/bndes_pt/Institucional/Sala_de_Imprensa/ Noticias/2011/industria/20110606_eldorado.html> (Acesso em 09/01/2013).

BRANDÃO, C. R. Território e desenvolvimento - as múltiplas escalas entre o local e o global. Campinas: UNICAMP, 2007.

CAMPACHE, S. A.; SILVA, G. P. Relações de trabalho em Três Lagoas-MS: industrialização recente, uma perspectiva de análise. in: X Encontro de História de Mato Grosso do Sul/ I Simpósio Internacional de História/ XIII Semana de História da UFMS/CPTL, Anais... Três Lagoas, 2010. p. 1878-1891. 
CHESNAIS, F. A mundialização do capital. São Paulo: Xamã, 1996.

CORREAA, R. L. Espaço, um conceito-chave da Geografia. In: CASTRO, I. E. de. et al. Geografia - Conceitos e Temas. Rio de Janeiro: Bertrand Brasil, 1995.

DAURA, S. P. Análise do setor de celulose e papel na era da globalização: um olhar sobre sua produção e mão-de-obra. 2004. 226 p. Dissertação (mestrado em Ciências Sociais). Universidade Estadual Paulista, Campus de Marília.

ÉPOCANEGÓCIOS. Três Lagoas - capital mundial da celulose. São Paulo, 04/10/2010. Disponível em: <http:// epocanegocios.globo.com/Revista/Common/0,,EMI177058-16642-6,00-> TRES+LAGOAS+CAPITAL +MUNDIAL+DA+CELULOSE.html> (Acesso em 20/11/2010).

FOLHA DE SÃO PAULO. Florestas avançam para novas fronteiras. São Paulo, 04/10/2011. Disponível em: <http://www1.folha.uol.com.br/mercado/993589-florestas-avancam-para-novas-fronteiras.shtml> (Acesso em 20/11/2011).

GAUDEMAR, J-P. de. Mobilidade do trabalho e acumulação do capital. Lisboa: Editorial Estampa, 1977. GOMES, F. G. Mobilidade do trabalho e controle social: trabalho e organizações na era neoliberal. Rev. Sociol. Polit. [online], São Paulo, p. 33-49, v.17, n.32, 2009.

HAESBAERT, R. O mito da desterritorialização. Rio de Janeiro: Bertrand Brasil, 2010.

HARNECKER, M. Os conceitos elementares do materialismo histórico. São Paulo: Global, 1973.

HARVEY, D. A produção capitalista do espaço. São Paulo: Annablume, 2005.

JURADO, L. S. O processo de industrialização na cidade de Três Lagoas (MS): discursos, desdobramentos e contradições. 2008. Dissertação (mestrado em Geografia) Universidade Federal de Mato Grosso do Sul, Campus de Aquidauana/MS.

JUVENAL, T. L.; MATTOS, R. L. G. O setor de celulose e papel. In: BNDES. BNDES 50 anos: Histórias Setoriais. 2002. Disponível em: <http://www.bndes.gov.br/SiteBNDES/export/sites/default/bndes_pt/Galerias/Arquivos/conhecimento/livro_setorial/setorial04.pdf $>$ (Acesso em 10/09/2011).

KUDLAVICZ, M. Dinâmica agrária e a territorialização do complexo Celulose/papel na microrregião de três lagoas/MS. 176p. 2011. Dissertação (mestrado em Geografia), Universidade Federal de Mato Grosso do Sul, Campus de Três Lagoas/MS.

MARANDOLA JÚNIOR. E. Os novos significados da mobilidade. Revista Brasileira de estudos da População, São Paulo, vol.25 nº 1, Jan./Junho, 2008.

MATTOSO, J. E. L. A desordem do trabalho. São Paulo: Página aberta, 1995.

MATO GROSSO DO SUL (estado). Lei no 3.839, de 28 de dezembro de 2009. Diário Oficial [do estado de Mato Grosso do Sul], Campo Grande, n. 7.612. 68p. 29 dez. 2009. Disponível em: <//ww1.imprensaoficial. ms.gov.br/pdf/supplements/DO7612_29_12_2009_SUP01.pdf> (Acesso em 10/05/2011).

MATO GROSSO DO SUL (estado)/SEPLANCT. Cenários e estratégias de longo prazo para Mato Grosso do Sul - MS 2020. Campo Grande, 1999.

MATO GROSSO DO SUL (estado)/SEPLANCT. Cerários e estratégias de longo prazo - MS 2025: caminhos para o desenvolvimento. Campo Grande: 2004.

MATO GROSSO DO SUL (estado)/SEPROTUR/SEBRAE-MS. Plano Estadual para o desenvolvimento sustentável de Florestas Plantadas (resumo executivo). Campo Grande, MS, Mar. 2009. Disponível em: $<$ http://www.pantanalecoturismo.tur.br/fotos/arquivos/916.pdf > (Acesso em 09/01/2012).

MÉSZÁROS, I. O desafio e o fardo do tempo histórico: o socialismo no século XXI. São Paulo: Boitempo, 2007. (Col. Mundo do Trabalho).

MÉSZÁROS, I. Para além do capital: rumo a uma teoria da transição. São Paulo: Boitempo, 2011.

MONTEBELLO, A. E. S.; BACHA, C.J.C. Estrutura de mercado e desempenho da indústria brasileira de celulose: período de 1980 a 2005. Pesquisa \& debate, São Paulo, p. 83-104, v. 18, nº 1 (31), 2007.

MOREIRA, R. Os períodos técnicos e os paradigmas do espaço do trabalho. Revista Ciência Geográfica, Bauru: AGB, p. 04-08, vol. II, no 16, ano 6, 2000.

MORELLI, L. A. A Monocultura do Eucalipto e a Monopolização do Território na Metade Sul do Rio Grande Do Sul. 2011. 209p. Tese (Doutorado) - Instituto de Geociências, Departamento de Geografia, 
Universidade Federal do Rio Grande do Sul, Porto Alegre, 2011.

PAKKASVIRTA, J. Fábricas de celulosa: historias de la globalizacion. Buenos Aires: La Colmena, 2010. PNUMA. Rumo a uma Economia Verde. Caminhos para o Desenvolvimento Sustentável e a Erradicação da Pobreza - Síntese para Tomadores de Decisão. 2011. Disponível em: <www.unep.org/greeneconomy > (Acesso em 10/08/2012).

REPORTER BRASIL (Org.). "Deserto Verde" - Os impactos do cultivo de eucalipto e pinus no Brasil. (Cartilha com distribuição gratuita). 2011.

ROCHA, Márcio Mendes. A espacialidade das mobilidades humanas - um olhar para o Norte-Central paranaense. 1998. 186f. Tese (doutorado em Geografia). Departamento de Geografia da Faculdade de Filosofia, Letras e Ciências Humanas, Universidade de São Paulo (FFLCH/USP), São Paulo.

SANTOS, J. R. dos. A Constituição do Complexo Agroindustrial de Celulose no Rio Grande do Sul: uma Avaliação da Dinâmica Global e da Inserção Brasileira no Setor. In: XII Encuentro de Geografos de America Latina, Annales... Montevideo, Uruguai, 2009. s/p.

SANTOS, M. Técnica, espaço, tempo: globalização e meio técnico-científico-informacional. São Paulo: HUCITEC, 1994.

SANTOS, M.; SILVEIRA, M. L. O Brasil: território e sociedade no início do século XXI. Rio de Janeiro: Record, 2006. (9a ed.).

SINGER, P. Curso de introdução à economia política. Rio de Janeiro: Forense-Universitária, 1975.

SOJA, E. W. Geografias pós-modernas: a reafirmação do espaço na teoria social crítica. Rio de Janeiro: Jorge Zahar, 1993.

SMITH, N. Desenvolvimento desigual. Rio de Janeiro: Bertrand, 1988.

THOMAZ JUNIOR, A. Intemperismo do trabalho e as disputas territoriais contemporâneas. São Paulo, Revista da ANPEGE, V.7, $N^{\circ} 1,2011$. p. 307-329.

VILELA, M. J. A. Desafios ambientais da expansão do plantio de eucalipto no cerrado - Três Lagoas, MS, Brasil. Rev. Eletrônica da Associação de Geógrafos Brasileiros - Seção Três Lagoas - MS, nº 14, ano 8, p. 123-140, nov. 2011.

WRM (MOVIMENTO MUNDIAL PELAS FLORESTAS TROPICAIS). Boletim n $\mathbf{n}^{\mathbf{0}} 83$ do WRM. Edição em português. Montevideo (Uruguai), Junho de 2004. Disponível em:

$<$ http://www.wrm.org.uy/boletim/83/opiniao.html> (Acesso em 12/01/2012).

Trabalho enviado em janeiro de 2013

Trabalho aceito em fevereiro de 2013 